\title{
Work Life Balance in Nepalese Commercial Banks
}

\author{
Resham Raj Pathak \\ MPhil Scholar, TU \\ reshamrajpathak90@gmail.com
}

\begin{abstract}
Work life balance has always been an important issue in social sciences due to its significant influence on career choice, time management, stress management and other important aspects of day to day life of human beings. Moreover, it is universal phenomena. With this context, the study tries to explore and analyze the link between Working hour, income level and organizational support with work-life balance of employees working in selected commercial banks of Nepal. Moreover, the study seeks the necessity to formulate an apparent and specific organization policy to address work life balance in Nepalese Commercial banks.
\end{abstract}

Keywords; Work Life Balance, Working Hours, Organizational Support, Family Conflict, Time Management, Organizational Culture

\section{Introduction}

Finding work-life balance in today's anxiously paced world is no simpler task. Spending more time at work than at home means missing out on a rewarding personal life. Then again, due to challenges in personal life, such as caring of an aging parent or coping with marital problems, concentrating on job becomes difficult. Whether the problem is too much focus on work or too little, the work life and personal life feel out of balance, lack of personal and work achievement being the ultimate result. Three major factors which contributes to the interest in and importance of work life balance, are global competition, renewed interest on personal lives-family value and aging work force. Researchers suggest that only forward thinking human resource professionals, one who seek innovative way to augment their organization's competitive advantage in their market place, may realize that tackling work life conflict offers a win-win solution (Green, 2001). WLB, from the employee perspective, is the maintenance of a balance between responsibilities at work and at home. Employers view the benefits or the working conditions that they provide to 
help employees balance the family and the work domains as work life benefits. Initially, the concept of work life conflict focused on the impact of family demands on work. It now extends to the impact work has on individual stress, relationships and family well-being (Abalkhail \& Allan, 2015).

\section{Research Issue}

Work-to-family conflict occurs when experiences at work interfere with family life inflexible working hours, work overload, interpersonal conflict at work, unsupportive supervisor organization. Family-to-work conflict occurs when experiences in the family interfere with work life primary responsibility for children, elder care responsibilities, interpersonal conflict within the family unit, unsupportive family members. Rood and Holdnak (2013) found that the level of compensation has a significant effect toward employee's work satisfaction whereby compensation was referred as salary, commission and bonus.

Likewise, working time mismatches and negative effects of working hours especially in the context of countries with lower welfare level should further be explored and analyzed. However for the case of 'overtime' as it relates closely to working hours, is of more or less voluntary in nature and compensated (Holly and Mohnen, 2012).

McCarthy, Cleveland, Hunter, Darcy \& Grady (2013) examined how employee perceptions of supervisory and organizational support for work-life balance, in addition to the number of work-life balance programmes available, predicted a number of work-life balance outcomes including role conflict, job satisfaction, family satisfaction and turnover intentions in a sample of large private and public sector organizations in Ireland. The attitudes of HR managers towards work-life balance programmes were also explored. To account for the nested structure of the data, analyses were conducted using hierarchical linear modeling. It was found that perceptions of work-life supportiveness as measured at the HR manager and immediate supervisor levels affect employee uptake of work life programmes, employee work-life balance outcomes and turnover intentions.

However, income level shall or shall not be directly related to work life balance due to prevalence of higher and diverse role expectation of married women especially by family members that shall eventually misbalance work and life domains. Moreover, number of working hours and perceived organizational support is key unexplored questions to be addressed especially for the case of employees working in Nepalese commercial banks. Working life and personal life are two important aspects of human life. Work life is related with generation of income to fulfill basic needs of employee as well as his/her dependents. Employee may have dual responsibility . They are responsible for better performance in their jobs and at the same time equally responsible for the betterment of their family. Whether there is imbalance in such duality in the context of Nepal? Whether the Nepalese banking sector is aware towards work life balance of the employees?

Journal of Business and Social Sciences (JBSS) 


\section{Objective of the Study}

The main objective of the research paper is to examine the factors which affect work life balance in banking sector of Nepal. The specific objectives are as follows:

- To examine the relationship between working hours and work life balance.

- To examine the relationship between income and work life balance.

- To find out the relationship between perceived organizational support and work life balance.

$\bullet$

Hypothesis

H7: There is a negative relationship between working hours and work life balance.

H2: There is a positive relationship between income and work life balance

H3: There is positive relationship between organizational support and work life balance

\section{Literature Review}

Work-family conflict is considered to be an important issue in today's business world (Coleman \& Pencavel, 1993). In recent years, there has been an increasing interest in the conflict between work and family life domains, and recent studies highlight the conflict experienced by individuals between their roles in the family and at work, which is covered under the heading called work-family conflict. While the findings obtained mainly in Western countries and the related theories refer to the obvious relationship between work demands and work-family conflict, it is indicated that long working hours, duty and heavy work load have a direct influence on work-family conflict. Thus, it is essential to establish a successful balance between work and family domains so that several demands in both domains could be met efficiently, and the required resources could be attained and used easily (Ganster \& Perrewe, 2009).

Work-family conflict is defined as a consequence of inconsistent demands between the roles at work and in the family. In other words, work-family conflict exists when the expectations related to a certain role do not meet the requirements of the other role, preventing the efficient performance of that role. Therefore, it could be said that the conflict between work and family domains tends to stem from the conflict between the roles. Several studies reveal that work and family are not two separate domains as they are highly interdependent, having a dynamic relation with one another. While family life is affected by the factors at work, the reverse is also experienced (Green, 2001).

Furthermore, many studies have pointed out that workforce turnover should be seen as a consequence of the cleavage between management and employees. Work-life balance policies can stimulate productivity and contribute to a healthier workplace and the more competitive. Moreover, resorting to flexible policies in organizations prevents the negative outcomes of work stressors on family satisfaction. The necessity for worklife balance initiatives in developed societies is triggered by the contemporary work mutations (Thomas, 2014).

Adjusting to the workplace culture, whether in a new company or not, can be 
intensely stressful. Making one adapt to the various aspects of workplace culture such as communication patterns, hierarchy, dress code if any, workspace and most importantly working and behavioral patterns of the boss as well as the co-workers, can be a lesson of life. Maladjustment to workplace cultures may lead to subtle conflicts with colleagues or even with superiors. In many cases office politics or gossips can be major stress inducers. Primary and secondary interventions may prevent adverse outcomes by reducing or eliminating external loads, changing organizational factors, altering the social environment, improving individual stress-coping skills, or matching the physical demands of the job with the employee's physical capacities

Figure 1

Theoretical Framework

Independent variables

Dependant variable

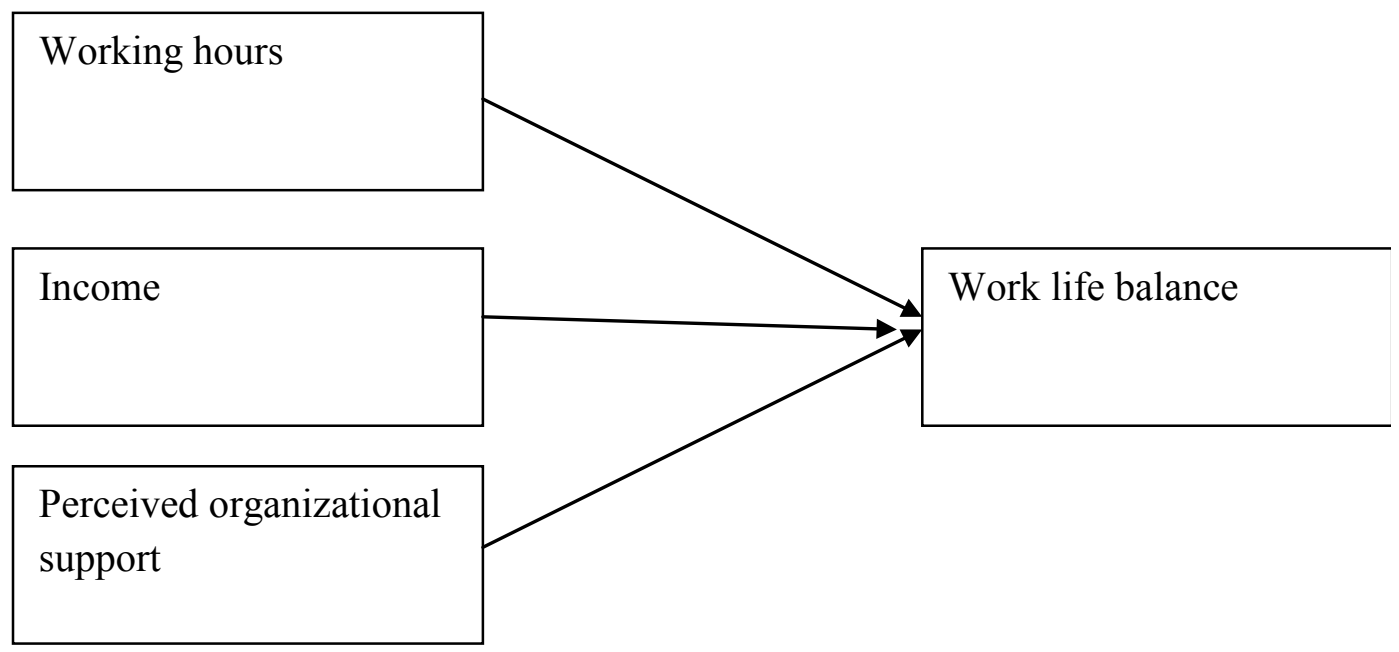

\section{Research Methodology}

The research has adopted descriptive and analytical research design. The exploratory factor analysis has been used to identify the relevant items and constructs in Nepali context. Similarly, the relationship between independent and dependant variables was identified using correlation analysis. The data was collected through five commercial banks located in Kathmandu: Siddhartha bank limited, Sanima Bank Limited, Prime Commercial Bank Limited, Global IME Bank Limited and Nepal Investment Bank Limited. The respondents were all married employees. The study determines sample size of 51 cases. The sample size for the study was determined on the basis of convenience and hence follows the non probabilistic sampling method however on the methodological standpoint, 50 cases may be adequate for factor analysis (Sapnas \& Zeller, 2002).

The respondents were asked to solicit their response on Structured Administered Questionnaire which consisted of two major parts. The first part of the questionnaire was 
related to general information such as Job title of the employees, hours spent at work per day, status of having children, and other demographic variables such as gender and age. The second part of the questionnaire consisted of Likert scale items ranging from strongly disagree (1) to strongly agree (5). The likert scale was consisted of 7 items that were related to two major construct i.e. organizational support and work life balance. Moreover, one question was related to Income. The final question was open ended in nature that asked respondents to share information about initiations taken by the bank to maintain job-family balance.

All the respondents were asked to fill up the questionnaire in their respective banks. At the initial stage, the respective banks in charge were consulted in order to seek for approval to collect the information for the purpose of academic research. Then the individual employees who were present on the day of the research and agreed to provide the information were distributed the questionnaire. Firstly, the entire questionnaire was given a unique code number and the data file was prepared in statistical software SPSS according to the variables included in the questionnaire.

Reliability refers to the consistency and stability of findings that enables findings to be replicated (Burns \& Burns, 2008). Chronbach's Alpha is used to measure the internal consistency of items (Cooper, Schindler, \& Sharma, 2012). Reliability refers to stability or consistency of measures: that is whether or not the same results would be achieved if the test or measures was applied repeatedly (Creswell, 2008). An alpha of 0.8 or above is regarded as highly acceptable for assuming homogeneity of items, while 0.7 is the limit of acceptability (Burns \& Burns, 2008).

Table 1

Reliability Analysis

\begin{tabular}{lccc}
\hline Construct & Chronbach'sAlpha & No of Item & Comments \\
\hline Organizational support & .715 & 4 & Accepted \\
Work life balance & .701 & 3 & Accepted \\
\hline
\end{tabular}

Kaiser Meyer Olkin measure of sampling adequacy statistics turned out to be .719 which indicates the data is suitable for factor analysis. KMO correlation above $0.60-$ 0.70 is considered adequate for analyzing the Exploratory Factor Analysis (EFA) output (Netemeyer, Bearden et al., 2003). Instrument validity can be measured by factor analysis. Factor analysis provides construct validity evidence of self-reporting scales (Gorsuch, 1983); (Tompson, 2004). Exploratory factor analysis is used to identify the underlying factors or latent variables for a set of variables (Harrington, 2009). Before conducting factor analysis it is necessary to analyzed whether EFA is the most appropriate statistical method to determine the construct validity or not.

\section{Factor Analysis}

Communalities

It explains the impact of items in latent variables which is the basis to decide which items are to be retained and which are to be dropped. 
Table 2

Communalities

\section{Items}

Extraction

The organization fails to appreciate any extra effort from me.

.383

The organization would ignore any complaint from me.

Even if I did the best job possible, the organization would fail to notice.

The organization shows very little concern for me.

My job responsibility overlaps family responsibility

My family responsibility overlaps my job responsibility

My job domains are greater than family responsibility

No items are dropped since the value of all items are greater than 0.3 total variance explain is 51.927

\section{Convergent Validity}

In order to examine the underlying structure of the 7 items, exploratory factor analysis using Maximum Likelihood method with Promax with Kaiser Normalization was conducted.

Table 3

Pattern Matrix

\section{Items}

Even if I did the best job possible, the organization would fail to notice.

The organization fails to appreciate any extra effort from me.

The organization would ignore any complaint from me.

My job domains are greater than family responsibility

My job responsibility overlaps family responsibility

The organization shows very little concern for me.

My family responsibility overlaps my job responsibility

Extraction Method: Maximum Likelihood.

Rotation Method: Promax with Kaiser Normalization.

Rotation converged in 3 iterations.

No cross loading, no negative loading and Individual loading were greater than 0.5 , implied there was convergent validity.

Journal of Business and Social Sciences (JBSS) 


\section{Discriminant Validity}

Overlapping of factors with each is the problem of multicollinearity. It is detected with the help of factor correlation matrix. When square of factor correlation is greater than 0.7 it indicates multicollinearity.

Table 4

Factor Correlation Matrix

\begin{tabular}{lrrr}
\hline & Factor & 1 & \multicolumn{1}{c}{2} \\
\hline 1 & & 1.000 & .406 \\
2 & .406 & 1.000
\end{tabular}

Extraction Method: Maximum Likelihood.

Rotation Method: Promax with Kaiser Normalization.

No items are cross loaded and correlation matrix showed there is no correlation between the factors having the value greater than 0.70 showed good discriminant validity.

\section{Results \\ Descriptive Analysis}

Income, working Hour and organizational support were independent variables and work life balance was dependent variable of this study. Income is categorical variable with 5 categories' (First category was up to 350000 then 350001 to 450000,450001 to 2500000 and above 2500000 respectively); Working hour is categorical variable with three categories (first category was below 8 hours and second more than 8 hours respectively). organizational support determination variable had four construct namely 'The organization fails to appreciate any extra effort from me', The organization would ignore any complaint from me, even if I did the best job possible, the organization would fail to notice and the organization shows very little concern for me.

The dependent variable Work life balance had three construct which is my job domains are greater than family responsibility, my job responsibility overlaps family responsibility and my family responsibility overlaps my job responsibility.

\section{Annual Income}

The 31.4 percent of respondent were in first category of income which is 16 respondent .43 .1 percent were in second category with 22 respondent. 25.5 percent were in third category with 13 respondents.

\section{Organizational Support}

The research sought to find out from respondents if their organizational support as constructs of work life balance. Summated scale of organizational support was prepared.

The result for mean scores for organizational support was 10.0980 . It seemed clearly from the statistical result above that majority of the respondents agreed that 
organizational support, constructs of work life balance variable. The Standard deviation for organizational support is 3.03483 , the statistical result for standard deviation revealed the consistency of the organizational support variable.

\section{Working hours}

This study sought to find out from respondents if their working hour as constructs of work life balance. Summated scale of working hour was prepared. There was 82.4 percent of bank employees were working hours more than 8 hours per day. It seemed, there was no work life balance due to long working hours.

\section{Correlation Analysis}

A correlation is a statistical measurement of the relationship either positive or negative between two variables. Possible correlation ranges from -1 to +1 . A zero correlation indicates there is no relationship between the variables of the study. First alternative hypothesis of this study was $\mathrm{H} 1$ : There is positive relationship between income determinations and accounting knowledge. Relational hypothesis of the study was tested with the help of correlation between income determination and accounting knowledge.

Table 5

Correlation Matrix

\begin{tabular}{|c|c|c|c|c|c|}
\hline & $\begin{array}{l}\text { Number of } \\
\text { Childrens }\end{array}$ & $\begin{array}{l}\text { Annual } \\
\text { Income }\end{array}$ & $\begin{array}{l}\text { Organizational } \\
\text { Support }\end{array}$ & $\begin{array}{l}\text { Hrs spent at } \\
\text { work/day }\end{array}$ & WLB \\
\hline Number of children & 1 & & & & \\
\hline Annual Income & $.310^{*}$ & 1 & & & \\
\hline Organizational Suppor & & $\begin{array}{l}.126 \\
.124\end{array}$ & 1 & & \\
\hline $\begin{array}{l}\text { Hrs spent at work/ } \\
\text { day }\end{array}$ & .080 & .142 & .206 & 1 & \\
\hline WLB & -.109 & -.137 & $.611^{* *}$ & .084 & 1 \\
\hline
\end{tabular}

First hypothesis of this study is, there is a negative relationship between working hours and work life balance. The correlation between working hour and work life balance revealed that there is no significant correlation between working hour and work life balance is 0.084 . It suggests the hypothesis should be rejected. The second hypothesis was there is a positive relationship between income and work life balance. The correlation between income and work life balance is $0 .-137$ suggest the hypothesis is rejected. It implies there is negative relationship between income and work life balance. The third hypothesis was there is positive relationship between organizational support and work life balance. The correlation between organizational support and work life balance is 0.611 suggest the hypothesis is accepted. It implies that there is significant positive relationship between work life balance and organizational support. 


\section{Conclusion}

The study findings regarding the positive relationship between organizational support and work life balance reveals the importance of organizational policies and its value for management of both work and life domains especially for the married employees with children's in case of banking industry of Nepal. The importance of such policies are highlighted in many previous studies as many studies have pointed out that workforce turnover should be seen as a consequence of the cleavage between management and employees (Voydanoff, 2005). Toffoletti \& Starr (2016) argued that work-life balance policies can stimulate productivity and contribute to a healthier workplace and the more competitive. Moreover, Callan (2008) posits in his studies that resorting to flexible policies in organizations prevents the negative outcomes of work stressors on family satisfaction.

Secondly, the Work life balance is about adjusting the working patterns to allow employees to combine work with their other responsibilities such as caring for children or elderly relatives. The study found the inverse relationship between the work life balance and number of children in the banking sector of Nepal. Family-to-work conflict occurs when experiences in the family interfere with work life primary responsibility for children, elder care responsibilities, interpersonal conflict within the family unit, unsupportive family members. Moreover, from the larger proportion of respondents reporting that they work more than 8 hours per day reveals the open fact that banking employee's work more than the statutory working hours due to their nature of job and an individual responsibility to reconcile and complete the work in a single day. In such case only allowing the incentives for the hours worked more than stipulated time frame would not solve the problem of work life balance because it leads for employee to involuntarily and undesirably allocate small proportion of time to family.

\section{References}

Abalkhail, J., \& Allan, B. (2015). Women's career advancement: mentoring and networking in Saudi Arabia and the UK. Human Resource Development International, 18(2), 153168. doi: 10.1080/13678868.2015.1026548

Burns, R. B., \& Burns, R. A. (2008). Business Research Methods and Statistics Using SPSS. London: SAGE Publications Lt.

Coleman, M., \& Pencavel, J. (1993). Changes in Work Hours of Male Employees, 19401988. Industrial And Labor Relations Review, 46(2), 262. doi: 10.2307/2524872

Cooper, D. R., Schindler, P. S., \& Sharma, J. K. (2012). Business Research Methods. New Delhi: Mc Graw Hill Education (India) Private Limited.

Creswell, J. W. (2008). Research Design: Qualitative. Quantitative and Mixed method Approaches. United Kingdom: Sage Publications.

Ganster, D., \& Perrewe, P. (2009). Employee health, coping and methodologies. Bingley: Emerald Group Publishing Limited.

Green, F. (2001). It's Been A Hard Day's Night: The Concentration and Intensification of Work in Late Twentieth-Century Britain. British Journal Of Industrial Relations, 39(1), 53-80. doi: 10.1111/1467-8543.00189

Gorsuch, R. (1983). Factor Analysis. Hillsadle, NJ: Eribaum. 
Harrington, D. (2009). Confirmatroy factor analysis: social work research method. oxford university press.

Holly, S., \& Mohnen, A. (2012). Impact of working hours on work-life balance (pp. 1-26). Berlin: SOEP.

McCarthy, A., Cleveland, J., Hunter, S., Darcy, C., \& Grady, G. (2013). Employee work-life balance outcomes in Ireland: a multilevel investigation of supervisory support and perceived organizational support. The International Journal Of Human Resource Management, 24(6), 1257-1276. doi: 10.1080/09585192.2012.709189

Rood, A., \& Holdnak, A. (2013). An Analysis of Compensation Patterns and Job Satisfaction Issues of Resort Recreation Professionals. Journal Of Tourism Insights, 4(1). doi: 10.9707/2328-0824.1038

Sapnas, K. G., \& Zeller, R. A. (2002). Minimizing sample size when using exploratory factor analysis for measurement. Journal of Nursing Measurement, 10 (2), 135-153.

Toffoletti, K., \& Starr, K. (2016). Women Academics and Work-Life Balance: Gendered Discourses of Work and Care. Gender, Work \& Organization, 23(5), 489-504. doi: $10.1111 /$ gwao. 12133

Thomas, K. (2014). Workplace Technology and the Creation of Boundaries. Advances In Developing Human Resources, 16(3), 281-295. doi: 10.1177/1523422314532092

Tompson, B. (2004). Explortory and confirmatory factor analysis: unerstanding concepts and applications. American Psychological Association .

Voydanoff, P. (2005). Toward a Conceptualization of Perceived Work-Family Fit and Balance:

A Demands and Resources Approach. Journal Of Marriage And Family, 67(4), 822-836. doi: $10.1111 /$ j.1741-3737.2005.00178.x 